\title{
Variable Air Volume System Design Guide
}

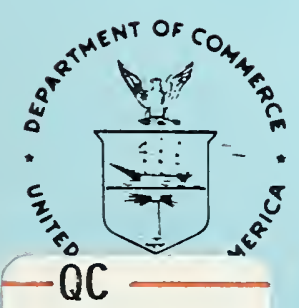

100

.456

4605

It of Commerce

1991

Ite of Standards and Technology ire Research Laboratory

UD 20899

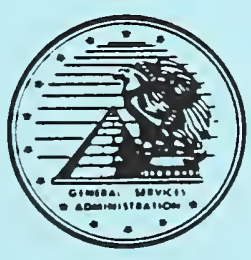

Prepared for:

General Services Administration

Public Buildings Service

Office of Real Property Development

Washington, DC 20405 



\section{Variable Air Volume System Design Guide}

James Y. Kao

June 1991

U.S. Department of Commerce

Robert A. Mosbacher, Secretary

National Institute of Standards and Technology

John W. Lyons, Director

Building and Fire Research Laboratory

Gaithersburg, MD 20899
Prepared for:

General Services Administration

Richard G. Austin, Administrator

Public Buildings Service

William C. Coleman, Commissioner

Office of Real Property Development

Washington, DC 20405 



\section{Abstract}

Variable air volume (VAV) systems have been used extensively in office buildings during recent years. However, there are persistent complaints by building occupants about the air quality and environmental conditions of these buildings. This guide has been developed to give guidelines on VAV system design to alleviate possible design-caused problems. This guide provides general discussion of VAV systems, air handling system design, system control, and commissioning.

This guide has been developed for the General Services Administration to be used by GSA personnel and GSA's contract designers. It includes design check lists as a means of identifying major aspects in VAV system design where new construction and alteration of air systems are involved.

Key Words: air conditioning, air handling system, automatic control, building design, design practice, variable air volume system 


\section{Table of Contents}

Page

Abstract.

CHAPTER 1. GENERAL

1.1 ADVANTAGES OF VARIABLE AIR VOLUME SYSTEM . . . . . . . . . . . 1

1.2 PROBLEMS OF VAV SYSTEM . . . . . . . . . . . . . . . . . . . . 2

1.3 SYSTEM SELECTION FOR SPACE COOLING AND HEATING . . . . . . . . 3

1.4 SYSTEM ANALYSIS . . . . . . . . . . . . . . . . . . . . . . . 3

1.5 GOOD DESIGN PRACTICE . . . . . . . . . . . . . . . . . . . . . 3

1.6 STRONG COMMUNICATION IN CONSTRUCTION DOCUMENTS . . . . . . . . 4

1.7 VAV SYSTEM AND SUBSYSTEM SELECTION . . . . . . . . . . . . . . 5

1.8 SYSTEM NOISE . . . . . . . . . . . . . . . . . . . . . . . . . 6

CHAPTER 2. AIR HANDLING SYSTEM DESIGN

2.1 DESIGN CRITERIA . . . . . . . . . . . . . . . . . . . . . . . 7

2.2 DESIGN CALCULATIONS . . . . . . . . . . . . . . . . . . . . . 8

2.3 SUPPLY AND RETURN AIR FANS . . . . . . . . . . . . . . . . . . 9

2.4 SUPPLY AIR DUCT SYSTEM . . . . . . . . . . . . . . . . . . . . 13

2.5 RETURN AIR SYSTEM . . . . . . . . . . . . . . . . . . . . . 14

2.6 SUPPLY AIR OUTLET . . . . . . . . . . . . . . . . . . . . 15

2.7 VAV TERMINAL UNIT . . . . . . . . . . . . . . . . . . . . . . 16

2.8 SPACE HEATING SYSTEM . . . . . . . . . . . . . . . . . . . . 16

2.9 SYSTEM PRESSURE PROFILE . . . . . . . . . . . . . . . . . . . 17

CHAPTER 3. SYSTEM CONTROL

3.1 SUPPLY DUCT STATIC PRESSURE CONTROL . . . . . . . . . . . . . 19

3.2 BUILDING PRESSURE MAINTENANCE . . . . . . . . . . . . . . . . 21

3.3 OUTDOOR AIR . . . . . . . . . . . . . . . . . . . . . . . . . . 24

3.4 CONTROL DETAILS . . . . . . . . . . . . . . . . . . . . . . . 25

CHAPTER 4. COMMISSIONING

4.1 VAV TERMINAL UNIT . . . . . . . . . . . . . . . . . 31

4.2 AIR OUTLET . . . . . . . . . . . . . . . . . . . . . . . 32

4.3 AIR HANDLING SYSTEM . . . . . . . . . . . . . . . . . . . 33 
Page

CHAPTER 5. DESIGN CHECK LIST

5.1 RECOMMENDED DESIGN PRACTICES . . . . . . . . . . . . . . . . . 35

5.2 ITEMS TO BE INCLUDED IN CONSTRUCTION DOCUMENT . . . . . . . . . 40

5.3 DESIGN ANALYSIS TO BE SUBMITTED TO PBS . . . . . . . . . . . . 42

REFERENCES CONTAINING USEFUL DESIGN DATA . . . . . . . . . 45 


\section{CHAPTER 1. GENERAL}

\subsection{ADVANTAGES OF VARIABLE AIR VOLUME SYSTEM}

The variable air volume (VAV) system is considered as the best choice among all-air systems for office buildings. The following advantages of VAV systems can be generally stated:

Energy Savings. The major benefit of applying VAV systems in office buildings is energy savings. By varying the amount of air supplied to spaces, system capacities match space loads. In a VAV system, the total amount of airflow rate of the supply air fan rarely exceeds $80 \%$ (building dependent) of the building block peak requirement during most of the operating time. Thus, the energy consumed for air transportation is kept to a minimum. In order to provide individual zone controls for temperature and humidity, most other all-air and air-water systems involve simultaneous heating and cooling. VAV systems accomplish space temperature control by reducing air flow to spaces. To a great extent during partial load conditions, simultaneous heating and cooling is avoided.

Air-Side Economizer Cycle. Although certain other systems may also match cooling capacity with space load (e.g. fan-coil system), a VAV system has the inherent benefit of any all-air systems to incorporate an economizer cycle during mild weather.

Individual space Control. Temperature control zones can be easily provided according to the desire of designers taking into account space load characteristics and other zoning requirements. Adding or deleting zones after building occupancy is also very flexible.

Moderately Low First Cost. The air handling unit and main ducts of a VAV system are sized smaller than those of other all-air systems by utilizing diversity of building loads. Savings in both equipment installation and space requirements may be realized.

Partial Operation of System. When incorporated in design, partial operation of a VAV system during off-hours is possible. It may be difficult to operate other all-air systems partially.

System Noise Reduction. As compared to unitary air conditioning systems and fan-coil systems, the noise sources (fans and compressors) are 
remotely located. When a VAV system is correctly designed, VAV terminal units act to reduce system noise.

\subsection{PROBLEMS OF VAV SYSTEM}

Since the supply air volume and duct pressure of a VAV system change in response to the building load changes, more engineering effort is needed to insure that the system is designed and maintained to operate satisfactorily at any building load conditions. Otherwise, unsatisfactory indoor comfort conditions and operation problems may result. In fact, numerous complaints about VAV systems have been cited frequently in recent years. If VAV systems are not designed and maintained properly, the following problems may appear:

Bullding Pressure Imbalance. Changing supply air, return air, and/or relief air quantities may upset the desired pressure level of a building, causing excessive air infiltration or building over-pressure. Unstable fan operation and fluctuating building pressure may also occur.

Inadequate Supply Air. Because of building load shifting, certain areas of the building may be starved for supply air resulting in over-heating and/or unbalanced air pressure between different areas of the building.

Noise Problem. Opposite of the inadequate air problem described above, the building load shifting may cause high duct pressure in certain areas of the building, resulting in noise complaints.

Uncomfortable Room Conditions at Partial Load. The reduced air movement during partial load may cause occupants to complain of warmth and stuffiness. The reduction of latent heat capacity of the supply air at partial load may cause unacceptable space humidity conditions.

Inadequate Outdoor Air. Depending on the system design, the outdoor air quantity may also be reduced following the supply air reduction, resulting in poor indoor air quality.

Cold Air Dumping. When supply air outlets are not selected correctly, cold supply air does not induce enough room air for mixing. Occupants may complain of cold during partial load conditions.

Poor Air Circulation in Rooms. It is a general practice of VAV system design not to use individual return air ducts in spaces. Poor selection and locations of supply air and return air outlets may cause short circuiting of airflow in spaces. 


\subsection{SYSTEM SELECTION FOR SPACE COOLING AND HEATING}

The economic benefits of VAV systems have been clearly demonstrated by numerous analysis and studies. A VAV system should be considered for design of any new and renovated Federal office building larger than 5000 square feet gross floor area. If a system other than a VAV system is selected, a life-cycle cost analysis should be prepared to prove that the selected system is more beneficial than a VAV system.

\subsection{SYSTEM ANALYSIS}

One of the reasons which precipitates VAV system design problems is historical. Since VAV systems gained popularity some 20 years ago, certain practices of designing constant volume systems have been inherited in designing VAV systems. These practices have resulted in inadequate system analysis of VAV design at building partial load conditions. In order to avoid the pitfalls of VAV problems, designers must perform system analysis to verify that all building areas served by the VAV system will perform satisfactorily at any anticipated building load conditions. The analysis shall be performed for at least two load conditions (system peak and system minimum) for systems serving single exposure areas and at least three load conditions (including system peak and system minimum) for systems serving multi-exposure areas. An interior zone shall be considered as a separate exposure for the performance analysis. Satisfactory performance of VAV terminal units located at two extremes (the first and the last units) of each branch ducts shall be demonstrated in the analysis. Detailed design requirements will be given in other chapters of this Guide.

\subsection{GOOD DESIGN PRACTICE}

A VAV system is only part of the entire HVAC system of a building. The performance of a VAV system not only depends on the particular design and operation of the system, it is also heavily influenced by other subsystems of the building. Important factors which may affect the performance of a VAV system are chilled water adequacy and temperature, intake air quality, and even the architectural arrangement of the building. Many occupant complaints and operational problems which seem to be caused by VAV systems are actually problems of general design and construction nature. Satisfactory operation of a building depends on good practices of all design areas as well as successful installation and operation. Although the scope of this document is limited to VAV systems and their related subsystems, special attention is advised for HVAC designers to exercise prudent design practices in cooling plant, cooling distribution, heating systems, associated air systems, and other 
related work.

\subsection{STRONG COMMUNICATION IN CONSTRUCTION DOCUMENTS}

The importance of system analyses is stated in previous sections. The benefits of these analyses do not end in the design office and must be relayed to construction and operation personnel. Designers should realize that they are the only persons involved in the project who have the responsibility of producing comprehensive analysis data of the system. Although performance type construction documents generally used in Federal projects do not emphasize construction details, critical information (e.g. duct static pressure setting for controlling fan) should be included. In fact, any critical information resulting from system analysis must be included in construction documents for Federal office buildings.

Satisfactory building operation depends very much on the knowledge of building operators. The most effective way building operators can fully understand the operation details of the VAV system and the system design philosophy is by having the designers communicate this information through operating manuals compiled by the construction contractors as required in the design documents. There also are many instances where the VAV systems are modified by operators because of certain operating problems. However, many of these modifications are not compatible with designers' design principles and ideas. Under the operation and maintenance sections of the specification, designers should instruct project contractors to include detailed operating procedures, possible failures, trouble shooting, and corrective measures in operation and maintenance manuals. Needless to say this information must first be given to the contractors through the construction documents.

The general qualifications of the operators are also important for successful building operations. The specifications should strengthen training requirements, especially for system automatic controls. Formal training classes appropriate for the project size and complexity should be specified to include a number of training days and training material outlines.

Many of the problems resulting from poor construction practices can be improved by tighter inspection and by instituting better commissioning procedures during construction. The time to establish these requirements is during the project design stage (see CHAPTER 4 for commissioning requirements). 


\subsection{VAV SYSTEM AND SUBSYSTEM SELECTION}

Selecting A Simple System. The selection of HVAC systems is based on the building's load characteristics and economics (construction and operating costs). It is entirely the designer's responsibility, utilizing the designer's knowledge and judgement. This Guide can only stress certain principles.

There are various types and arrangements of VAV systems being designed and operated in Federal office buildings. The selection of a particular VAV system should be based on the designer's analysis of the building site, building construction, load variations, system installation cost, system operating cost, and other pertinent considerations. It is usually also influenced by the designer's personal preference and inclination. Designers must keep in mind that the best system is a simple system which can accomplish the required objectives. However, simplicity does not imply compromising system performance. A system which can not accomplish desired and available functions is not a simple system. The following discussion may assist designers in considering system simplicity:

Return Air Fan. The airflow relationship of supply/return air fans often causes operational problems in buildings (see more discussion in other chapters). For a system where return air ducts are short, the system without a return air fan should be considered. However, if the total return air duct friction is more than $62 \mathrm{~Pa}\left(0.25 " \mathrm{H}_{2} \mathrm{O}\right.$ ) (from the rooms to the return air duct connection at the air handling unit), use of a return air fan should be considered. A system having a long return air duct and without a return air fan may exert too much negative pressure on the suction side of the fan (thus the air handling unit plenum) and create difficulty in balancing of outside air and return air. When the economizer cycle is applied in such a system, the air balancing problem is further exacerbated.

Pressure Dependent VAV. Pressure dependent terminal units are less expensive and simpler to operate than pressure independent units. However, static pressure fluctuation in supply air ducts may cause excessive air supply and unstable airflow in pressure dependent units. For small office buildings where the duct pressure variations are not severe (less than $250 \mathrm{~Pa}\left(1 " \mathrm{H}_{2} \mathrm{O}\right)$ ), pressure dependent units should be considered. Most Federal office buildings are of medium size and height (over 4,645 $\mathrm{m}^{2}\left(50,000 \mathrm{ft}^{2}\right)$ gross floor area and over three stories high). If a VAV system over $4,720 \mathrm{~L} / \mathrm{s}(10,000 \mathrm{cfm})$ peak fan supply air is contemplated, a pressure independent type should always be considered.

Bypass VAV. This type of VAV system bypasses a portion of the supply air to the ceiling space under the control of space temperature 
controllers. The total air quantities transported by the supply/return fans remain unchanged regardless of the magnitude of the building load. Energy savings of this type of system are limited only to the cooling load reduction. There is no saving on fan energy. Use of bypass type is not recommended.

Single-duct VAV. Dampers of a single-duct VAV terminal unit respond to the space cooling load to vary the airflow rate. At low space load conditions, the supply air temperature may be reset upward to increase airflow to alleviate room stuffiness (see other chapters for more discussion of temperature reset). Reheat coils may also be included in the design to supply heat. This type of VAV system is probably the least complicated system and shall be considered as a baseline selection in all Federal buildings.

Fan-Powered VAV. The VAV terminal unit contains a fan either in series or in parallel to the cold supply air. A reheat coil may also be added to supply heat. Since the series-fan type have the unit fan operating continuously, it is difficult to balance the system. This type usually has a higher operating cost (maintenance cost and possibly energy cost), and its use is not recommended. The main advantages of the parallel-fan type system are its ability to utilize the warm ceiling air to heat the rooms and its ability to increase space air movement at low load conditions. The disadvantages of parallel-fan system are the increased operating cost and the intermittent noise produced by the fan operation.

More discussion of system selection is given in CHAPTER 2 AIR HANDLING SYSTEM DESIGN.

\subsection{SYSTEM NOISE}

Air handling system noise and its attenuation are well covered in many publications on HVAC design practices (such as ASHRAE Handbooks). However, VAV air handling systems may create additional noise problems due to variations of air flow caused by building load changes. Fans, air distribution ducts, VAV terminal units, and air outlets may all contribute to room noise problems. Designers must make certain that the equipment noise generation and abatement (by both air system itself and the added attenuation equipment) will meet the required noise levels of the spaces. 


\section{CHAPTER 2. AIR HANDLING SYSTEM DESIGN}

Design of office buildings shall follow the requirements of PBS's Quality Standards for Design and Construction handbook (PBS P 3430.1A), except where modified in this document.

\subsection{DESIGN CRITERIA}

Outdoor. The recommended amount of outdoor air intake has recently been increased. For conference rooms, court rooms, and offices, $9.4 \mathrm{~L} / \mathrm{s}$ (20 cfm) per person shall be used. This amount of outdoor air must be maintained when the building is occupied.

Zoning of Office Spaces. One of the main causes of occupants' complaints of unsatisfactory space conditions is poor zoning arrangement. Temperature control zones must be determined by space load characteristics and program requirements. As a general principle, the maximum amount of operating energy may be saved with smaller zones when the spaces have substantial load variations and differences. Energy savings, of course, must also be evaluated with the increased construction cost. Unless otherwise required by PBS design directives, perimeter offices shall be limited to a maximum floor area of $93 \mathrm{~m}^{2}$ $\left(1,000 \mathrm{ft}^{2}\right)$. For interior partitioned offices, the maximum floor area of a zone shall also be limited to $93 \mathrm{~m}^{2}$ (1,000 $\left.\mathrm{ft}^{2}\right)$, providing the functions of individual rooms are similar. For interior open-office plans, each zone shall have a maximum floor area of $232 \mathrm{~m}^{2}(2,500 \mathrm{ft} 2)$.

Noise Level. General offices shall be designed for Room Criteria (RC) 35 and conference rooms shall be designed for RC 30. The maximum allowed noise levels of supply air fans and VAV terminal units shall be specified in the construction documents.

Court Room. Court rooms have load characteristics and use schedules substantially different from those of offices. From the point of view of temperature and humidity control, outdoor air requirements, and energy savings, court rooms should have separate air handling units. Since the load variation of court rooms is usually severe and the sensible heat ratios (room sensible heat/room total heat) of court rooms may vary between extremes, use of VAV systems in these rooms requires careful consideration. If a VAV system is used, the minimum supply 
airflow rate should not drop below $50 \%$ of the peak supply air, unless calculations prove otherwise. Raise the supply air temperature or reheat the supply air when the room load decreases below $50 \%$ of the peak load.

\subsection{DESIGN CALCULATIONS}

Room Load. In addition to peak room load, room load and conditions must be calculated for minimum supply air rate to insure that the space humidity will not exceed the design criteria requirements. A typical room calculation is adequate for interior rooms of similar load characteristics. Room humidity levels at minimum airflow rates must be checked for all low sensible-heat-ratio rooms, such as conference rooms, court rooms, and rooms with moisture-releasing equipment.

Room Supply Air. The amount of room peak supply air shall be based on room load calculations, but it shall not be less than $3.6 \mathrm{~L} / \mathrm{s}$ for each square meter $(0.7 \mathrm{cfm}$ for each square foot) of floor area.

Room Minimum Air Supply. The determination of room minimum supply air is based on many factors. Room load variation, space humidity level, air movement in occupied zone at minimum supply air, means of space temperature control, and the effect of overall system minimum air to fan operation should all be considered. For individual rooms, the minimum supply air should not be below $30 \%$ of the maximum supply air. Both the maximum and the minimum supply air amounts of VAV terminal units shall be scheduled in the construction documents.

System Block Load. Each VAV system must have block loads calculated at several possible peak times in order to determine the maximum load for sizing the air handling equipment and cooling plant. System peak load depends on building orientation, building construction, internal load changes, and other factors. At a minimum, system loads at 9 A.M., 12 noon, 2 P.M. and 4 P.M. must be calculated.

System Noise. Noise calculations on the first seven octave bands (from center frequency 63 to $4,000 \mathrm{~Hz}$ ) are required for supply air systems. Calculations shall be based on the building's peak block load (i.e. at maximum airflow rate) using representative sound data from equipment manufacturers. 


\subsection{SUPPLY AND RETURN AIR FANS}

Fan Selection. The type of fans selected for a system depends on performance (size, pressure, energy, etc.), space, cost, and the designer's preference. Forward-curved, backward-curved/backwardinclined, and airfoil centrifugal fans, and vaneaxial fans have all been used successfully in VAV systems. Since energy consumption of fans is one of the largest items of HVAC systems, careful evaluation of energy consequences of fan selection should be made. Generally, forward-curved fans are not as efficient as backward-curved/backward-inclined or airfoil fans. For the same duty, forward-curved fans are smaller in size than the other two types of fans and are used extensively by air handling unit manufacturers for packaged units. However, forward-curved fans should not be used in packaged units with fan wheels larger than $20 "$ in diameter or any built-up units.

Vaneaxial fans generally require less space, are more costly than centrifugal fans, and have high efficiencies. Airfoil blades are more efficient and quieter than single-thickness blades. Careful selection of vaneaxial fans to match the system requirements is especially important in order to achieve high efficiency and low noise.

Pay attention to the entire range of fan operation to make sure that at no time shall the fans (all types) operate in the surge areas of the fan curves. The size of the fan motors must also be checked so that the fans will not overload the motors along the entire operating range. This is especially important for forward-curved centrifugal and vaneaxial fans. Parallel fan arrangement with individual drives shall not be used in order to avoid the possibility of unstable operation.

For a VAV air handling fan, the selection of the fan size is a compromise between the overall yearly energy efficiency and fan stability. This is quite different from a constant volume air system where the fan size can be selected to yield the highest efficiency at all times. A VAV system fan should be selected smaller than the size which would give the highest efficiency at the peak block load. The small fan is more stable (having larger airflow range without running into the area of surge than that of a bigger fan) and gives better overall efficiency for the entire load variations. Ideally, extensive load and system performance calculations (hourly calculations for the entire year or methods based on yearly temperature frequency-BIN) would be required if such a fan selection is to be optimized. However, designers may use their judgement to select fans based on airflow rate of 60 - $80 \%$ of the peak block load requirement, with the large percent being used in less diversified system loads.

Fan noise is generally a reflection of fan static efficiency. A fan with the highest static efficiency is usually the quietest fan. For the 
sizes of air handling systems designed for Federal buildings, noise treatment is usually needed between the fan discharge and the ducts leaving the equipment room. Centrifugal fans generate most sound energy at low frequency octave bands while vaneaxial fans spread sound energy over most bands. After compensating for the human ear's selective sensitivity to the sound spectrum, vaneaxial fans usually require more noise treatment than centrifugal fans. Designers should consider the cost and space requirement of noise treatment when selecting fan type and size. For sound attenuation calculations, representative blade frequency increment (BFI) and sound power levels from fan manufacturers or the ASHRAE Handbook should be used. The maximum BFI and sound power level of critical octave bands should be specified in construction documents.

Designers should also realize that both the fan characteristics as presented by fan manufacturers (which are based on ideal test conditions) and the system curves as estimated by designers (which are affected by duct construction, field conditions, cooling coil and air filter conditions, etc.) may be different from those during operation. Certain adjustments of the fan operation from the design may be necessary.

Fan Flow Control. Fan flow control may be accomplished by throttling the fan's output along the fan's characteristic curve or by moving the operating points to different fan characteristic curves. Discharge dampers throttle the fan's output with very limited power savings. They shall not be used in VAV systems in Federal buildings. Air flow control by variable inlet vanes gives better energy performance than by discharge dampers. Properly designed variable inlet vanes reduce air turbulence entering the fan, and thus create different performance curves for the fan/inlet-vane combinations and improve fan power consumption. If inlet-vanes are used, designers should specify that they be designed for the particular fan and be supplied by the fan manufacturer. Note that inlet vanes sometimes also increase the fan sound power level.

The most efficient way to achieve fan flow control is to vary the speed of the fan. This essentially shifts the operating point of the fan among the fan's characteristic curves. There are various methods to change fan speed. Technological advances in electronics in the recent past have made variable frequency drives very reliable and competitive in cost. The adjustable frequency alternating-current (ac) drive changes voltage and frequency to give a lower speed, so the motor always operates at the maximum efficiency at partial load. There are other types of fan speed controls, such as variable sheave belt-drive, eddy current drive (magnetic coupling), etc., however they are bulky and require more maintenance. Similar to the variable frequency ac drive is the direct-current (dc) drive, which also varies the speed of the motor. 
The dc drive requires a special dc motor which is more complex than an ac squirrel-cage motor and requires additional maintenance. Because of the special dc motor, the dc drive/motor system. is generally higher in first cost than the ac drive/motor system. Additionally, the dc motor and fan must be out of service for repairs to be made to the controller, whereas an ac drive can be bypassed and the motor and fan can operate at base speed during an emergency.

Vaneaxial fans can usually be provided with adjustable pitch blade controls which change the fan geometry to vary the air flow rates. The power reduction during partial load is very good.

The choice of air flow control depends on the various specific requirements of the VAV system, including the amount of air to be removed, the system turndown ratio, and the pressure characteristics of the air distribution system. Generally, a variable frequency ac drive for a centrifugal fan or an adjustable pitch blade control for a vaneaxial fan is the preferred selection. For smaller air handling systems of $4,720 \mathrm{~L} / \mathrm{s}(10,000 \mathrm{cfm})$ or less, an inlet vane control is an option. The designer should use life-cycle comparisons to select the type of flow controls to be used. If a variable frequency drive is used, the invertor should simulate the sine wave using pulse width modulation. Designers should also make sure that the motor selected will suit the invertor specified.

Figure 1 illustrates a typical variable speed fan and system performance. As shown in this figure, fans must not be selected to operate at any load on the left side of the stable curve. A system operating curve similar to that of Figure 1 should be constructed by combining the system friction curve and the added static pressures at various loads. Note that this added static pressure varies at different system capacities due to a fixed setting of the duct static pressure control. This system operating curve and the fan stable curve determine the maximum airflow range of the system. Each VAV system must be analyzed during the course of the design. Specify airflow rates and pressures at both maximum and minimum capacities. Require fan manufacturers to prove stable operation in their submittals. 


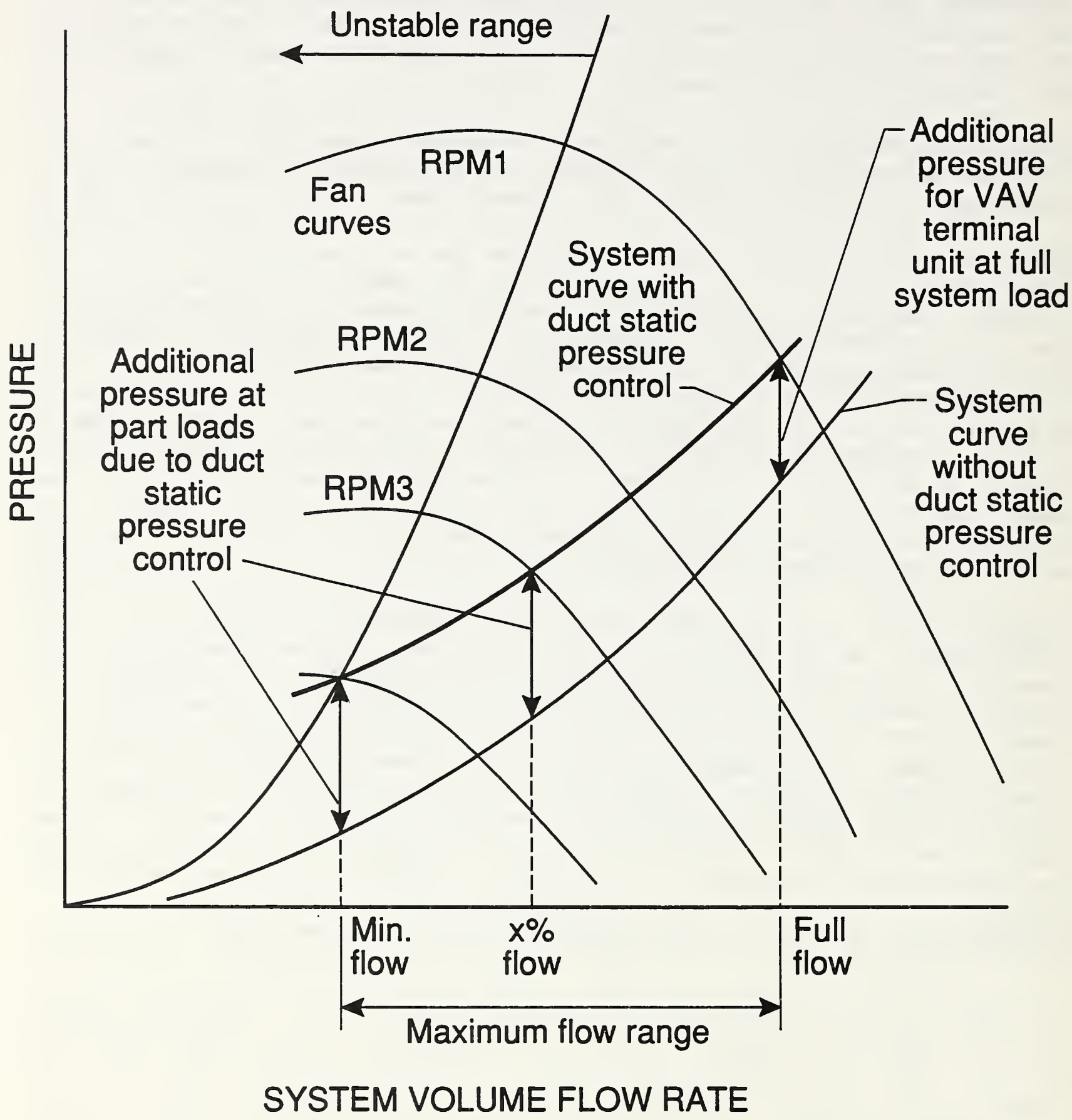

Figure 1. Illustration of Fan-System Matching for Supply Fan Operation 


\subsection{SUPPIY AIR DUCT SYSTEM}

Duct sizing. The principle of VAV system duct design is to maintain the static pressure in the duct system as stable as possible while the building load is changing. Static pressure regain method is the preferred choice and shall be used for sizing supply air ducts from air handling units to VAV terminal units. With this method, part of the velocity pressure of the upstream air is used to offset the duct friction, thus the static pressure in the downstream duct is kept relatively stable when the airflow rate changes. In order to avoid oversizing of ducts at end runs which may occur for long duct branches, the equal friction method may be used when the air velocity in the branches drops to below $6.4 \mathrm{~m} / \mathrm{s}(1,250 \mathrm{fpm})$. Airflow rates used for sizing ducts shall be the peak airflow rates flowing in those duct sections. For a branch duct serving the same building exposure or interior spaces, the peak airflow rates are usually the sums of individual room supply airflow rates. Perform duct sizing and air friction calculations for the entire supply duct system to include duct section, duct size, airflow rate, air velocity, pressure loss, pressure regain, and cumulative duct friction.

Supply Duct Pressure Calculations. Supply duct system pressure (including those of the air handling unit components) shall be calculated for the peak system load. System effect factors must be included in pressure calculations for fan selections (System effect factors are available in SMACNA HVAC Duct System Design, See REFERENCES at end of this Guide). If multi-branch (two branches and over) ducts are designed, at least one additional calculation shall be made at partial load.

Duct Configuration. For ducts from air handling units to VAV terminal units, round or oval ducts shall be used whenever possible. Flexible ducts are often used to connect VAV terminal units to supply ducts. The length of these flexible ducts should be limited to $1.5 \mathrm{~m}$ ( $5 \mathrm{ft}$ ) maximum. The sizes of connecting ducts must be the same as unit inlet sizes.

Ductwork Layout. Duct layout for a VAV system is more important and usually much more difficult than for a constant volume air system. It is often difficult to arrange ducts ideally in most buildings to avoid dynamic losses due to building structural restraints. However, extra effort must be made to minimize these losses. This is especially important for a VAV system with multiple duct branches. Designers should use calculations and judgment based on building load changes and system layout to anticipate possible airflow problems during partial load situations (Airflow in a branch duct may actually be higher during partial load than during system peak load). Depending on building orientation, shape and space arrangement, various preliminary duct 
layouts are necessary to reach the best arrangement. Low loss fittings should be used whenever possible. Observing recommended straight duct lengths between fittings is most important. In many cases, one way to alleviate extreme duct pressure fluctuations in a multi-branch duct system is to use an interconnecting (or loop) duct arrangement as illustrated in a real office building shown in Figure 2. This building has one air handling system located on the top floor. The main supply duct was installed under the top floor with various restrictions. Tests reveal that the main east and west branches on each floor often differ over $250 \mathrm{~Pa}\left(1 " \mathrm{H}_{2} \mathrm{O}\right)$ in static pressure. Interconnecting ducts as represented by the double-line could have been installed easily to alleviate operating difficulties and to gain energy savings.

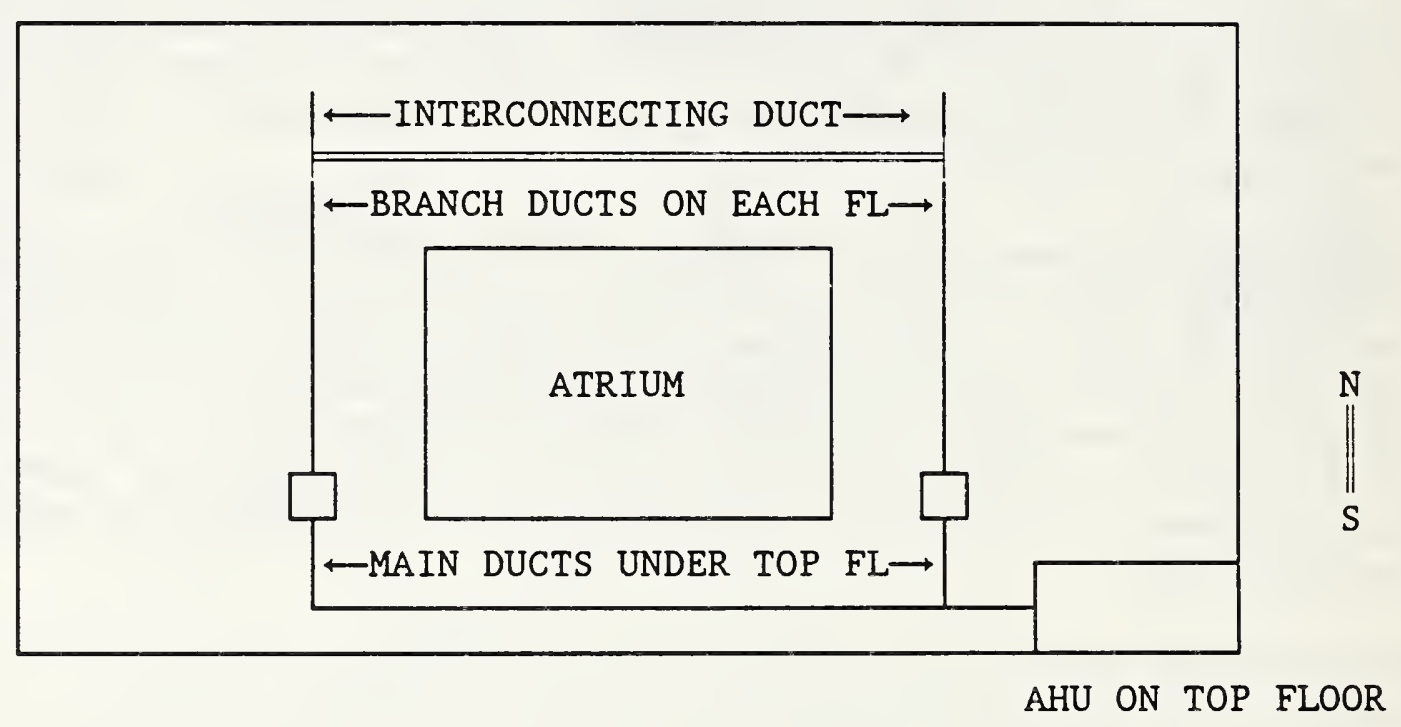

Figure 2. Example of Using Interconnecting Duct to Improve Performance

\subsection{RETURN AIR SYSTEM}

Return Air Duct Layout. Return air is usually designed to return through ceiling grilles to suspended ceiling spaces where the air is collected to return air ducts or shafts at a few central locations. For systems serving large areas, the collection of return air in ducts or shafts should be evenly distributed with a single return air inlet limited to $1,888 \mathrm{~L} / \mathrm{s}(4,000 \mathrm{cfm})$. The distance from the farthest ceiling grille to the inlet of duct or shaft should not be over $45 \mathrm{~m}$ (150 ft). 
Supply Air Short Circuiting. If the space air distribution pattern is not designed properly, a large portion of the supply air may bypass the rooms and return to the ceiling plenum without absorbing the room loads. This is especially true for supply air outlets close to the ceiling return air collection points. Designers should carefully evaluate the pressure gradients in the ceiling plenum and the relative locations of the supply and the return air outlets to insure that no short-circuiting will occur. For any return air collection point in ceiling space having over $944 \mathrm{~L} / \mathrm{s}(2,000 \mathrm{cfm})$, the return air within $6 \mathrm{~m}(20 \mathrm{ft})$ from the collection point should have low return grilles in place of ceiling grilles.

\subsection{SUPPLY AIR OUTLET}

Special Requirements for VAV Systems. The selection of outlets for VAV systems requires more careful consideration than for constant air volume applications. Many complaints of excessive cooling occur during low load (thus low flow) conditions when the supply air is "dumped" from the air outlets. Many complaints of room stuffiness are also due to poor performance of air outlets. As a general principle, high entrainment types of outlets should be selected. Air outlet selection criteria are usually based on (other than aesthetic, space, and thermal requirements) flow rate, throw, drop, spread, noise level, and pressure requirements. Since air flow rates may vary substantially for VAV systems, if the minimum air flow rate is below $50 \%$ of the maximum air flow rate, the Air Diffusion Performance Index (ADPI) for cooling should be checked for both maximum and minimum air flows for each supply air outlet. For outlets with the minimum air flow rate higher than $50 \%$ of the maximum air flow rate, only the ADPI for maximum flow rate needs to be checked. The ADPI for cooling should not be below $80 \%$ at a $0.5 \mathrm{~m} / \mathrm{s}$ (100 fpm) terminal velocity of the throw for ceiling slot diffusers and at a 0.25 $\mathrm{m} / \mathrm{s}$ (50 fpm) terminal velocity for other terminal devices. See Chapter 31, Space Air Diffusion, of ASHRAE 1989 Foundamentals Handbook for outlet selection procedures.

Direct Air Flow Horizontally. All supply air outlets should be specified to have adjustable or fixed air deflection means to direct air flow at a horizontal direction. Air flow following the ceiling plane can mix well with induced room air at low load (low flow) conditions. Linear strip diffusers with deflection blades have been used successfully for many VAV systems. If the length of linear diffusers is longer than $1.5 \mathrm{~m}$ ( $5 \mathrm{ft}$ ), multiple duct connections to the diffuser plenum at 1.5-meter ( 5 -foot) maximum intervals should be designed. Avoid using vertically discharged outlets (such as light troffers without deflection blades). Pay attention to obstructions and breaks of ceiling levels in locating ceiling outlets. 


\subsection{VAV TERMINAL UNIT}

Depending on the VAV system design, different variations of terminal units are available: single-duct cooling unit, single-duct cooling unit with reheat coil (electric or hot water), fan powered unit (with or without heating coil), dual-duct unit, and VAV induction unit. There are various designs and constructions of these units. One important part of a pressure independent VAV terminal is the mechanism that maintains the required airflow regardless of the static pressure change, within a certain limit, in the supply air duct. To compensate for static pressure fluctuations in the supply duct, a velocity or velocity pressure sensing device differing in physical principle and design is usually used to measure the airflow rate of the unit and to reset the damper position. Most unit manufacturers use the differential pressure approach which detects the total and the static pressures at the neck of the terminal unit. When the airflow is low at low room load, this velocity measuring scheme may produce a large error or may even lose its ability to detect the airflow.

The industry test standard for VAV terminal units (such as ARI Standard 880-89) requires airflow tests for the rated airflow and $50 \%$ of the rated airflow only. It is up to the designers to specify tight specifications if the required minimum air flow rates of a project go much below $50 \%$ of the terminal units' rated airflow rates. Recent field tests reveals that the performance of VAV terminal units varies substantially depending on the method and location of airflow sensing, damper operation, and the box and control package construction. Designers should require quality construction and performance by strengthening their specifications.

\subsection{SPACE HEATING SYSTEM}

Interlor Zones. Interior zones for general offices shall not be provided with heating means. Exceptions are conference rooms, court rooms, and other high latent load producing spaces. In order to control excessive humidity in these rooms, psychrometric analysis must be done for the anticipated load changes. If required, VAV terminal units with reheat coils or fan-powered units with reheat coils should be designed to prevent space humidity levels above $55 \%$ R.H.

Perimeter Zones. For comfort reasons, it is generally necessary to have heating supplied under windows in buildings where the $99 \%$ column of winter design dry-bulb conditions (ASHRAE 1989 Fundamentals Handbook, Chapter 24, Table 1 Climatic Conditions for the United States) are below $-1{ }^{\circ} \mathrm{C}\left(30^{\circ} \mathrm{F}\right)$. In choosing a space heating system, keep in mind that simplicity in system design is essential for successful operation in the 
future. One system which satisfies these requirements is the finnedtube radiation or convectors heating system under windows. The space temperature setting to invoke VAV cooling and the heating system should be separated by at least $2.8^{\circ} \mathrm{C}\left(5^{\circ} \mathrm{F}\right)$ to avoid simultaneous heating and cooling. For building locations having winter design dry-bulb temperature at $-1{ }^{\circ} \mathrm{C}\left(30^{\circ} \mathrm{F}\right)$ or over, alternate heating systems are available, such as overhead double-duct or fan-powered units with heating coils. Heating supplied by air inherently uses more fan energy, and there are other tradeoffs between these two heating means. Economic comparisons and maintenance justifications should be evaluated to determine the systems to be applied. If electric reheat coils are used in VAV terminal units, the heated air temperature at minimum airflows must be checked to be below $67^{\circ} \mathrm{C}\left(120^{\circ} \mathrm{F}\right)$.

\subsection{SYSTEM PRESSURE PROFILE}

The pressure within the entire VAV system changes constantly following the space load variations. Each VAV system must be analyzed for pressure changes for the entire air path. The air path includes outside environment, various locations in the air handling unit, the supply duct at fan discharge, take-off points at critical VAV terminal units, the conditioned room, the return air fan suction and discharge, and the point inside the return duct before the return air damper. It is useful during design to plot the pressure profiles of the system at different operating conditions to assure that the system will be performing satisfactorily when the building is constructed. Total pressure profiles shall be plotted for the following conditions:

At system peak load with economizer cycle off;

At system minimum load with economizer cycle off;

If the system has multi-branch supply air distribution, at approximately mid-point between system peak and system minimum loads with economizer cycle off; and

At system peak load with economizer cycle on.

More discussion on air handling system performance affected by economizer cycle is given in CHAPTER 3 SYSTEM CONTROL.

Figure 3 illustrates a total pressure profile of a typical VAV system. Points marked by (*) signs in the figure need special notice to insure proper system operation. Pressure levels at these points must be checked for proper system functioning and must be indicated in the pressure profiles. 

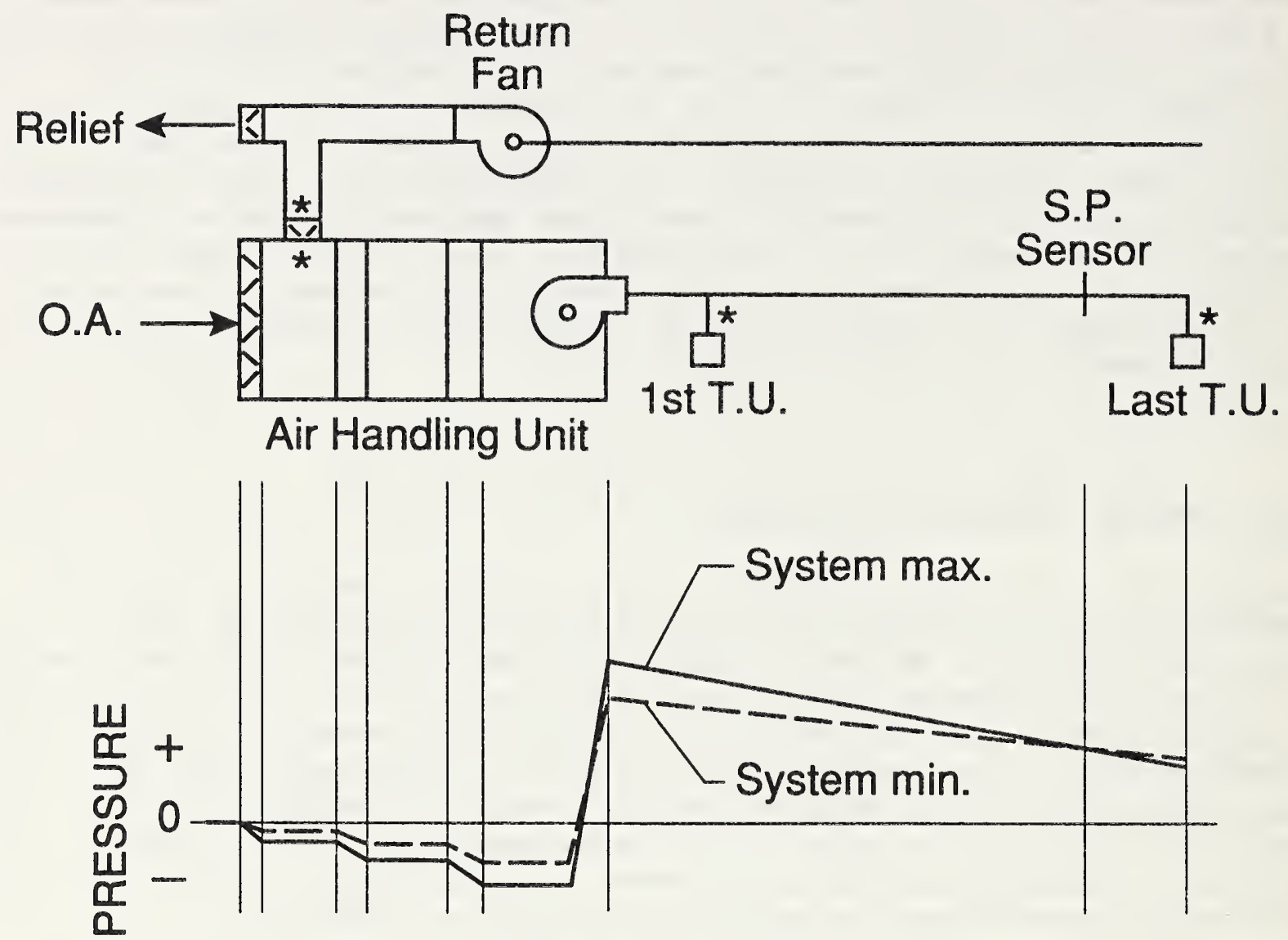

\section{Supply Air Path}

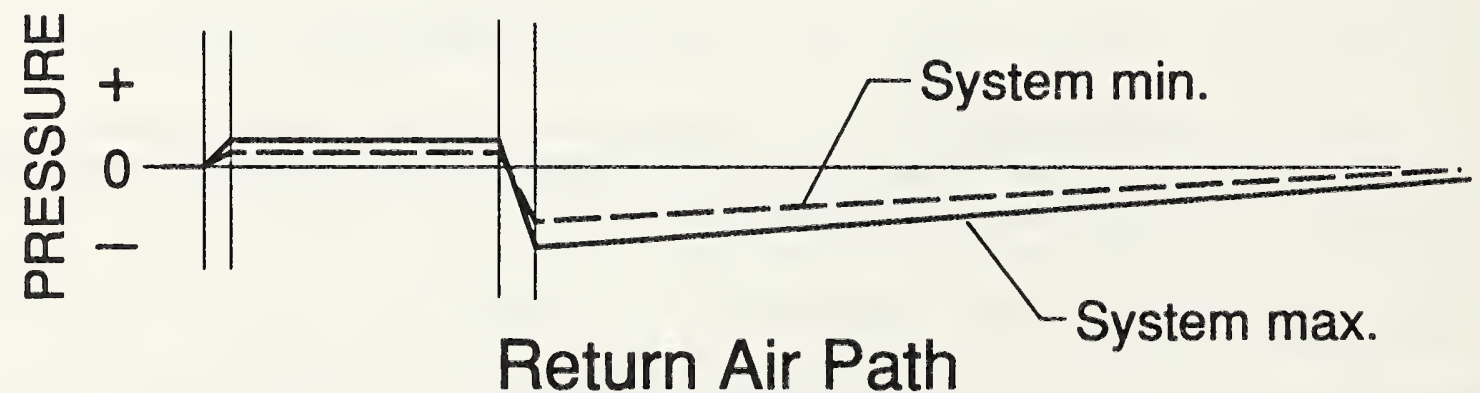

Figure 3 Illustrative Static Pressure Profile of A VAV system 


\section{CHAPTER 3. SYSTEM CONTROL}

Two of the major concerns in a VAV central system control are how to maintain supply duct static pressure and how to keep the building pressure stable. Both of these processes require accurate control and both must be examined together with the type of VAV systems and components used.

\subsection{SUPPLY DUCT STATIC PRESSURE CONTROL}

Supply Fan Control. The objective of static pressure control in supply ducts is to maintain static pressure within certain tolerances in all supply ducts at all times. All VAV terminal units can function properly regardless of the building load changes. This is usually accomplished by a fan control loop. In this loop, a static pressure controller compares the actual supply duct static pressure to the static pressure setpoint and modulates the fan control through adjustable frequency controller, variable pitch blade actuator, or inlet vane actuator.

Control Modes. With a proportional (P) controller, an inherent offset is present when the control is in action. Recycling is often experienced after a process change. A proportional-integral (PI) controller resets the control responses and eliminates this offset. A proportional-integral-derivative (PID) controller senses the rate of change of the error and brings the duct static pressure to the setpoint without much recycling after a process change. Since this offset injects an error into the level of the duct static pressure, and in the case of a VAV system the error tends to have higher pressure than the setpoint, substantial energy is wasted at off-load conditions. Therefore, all supply fans in VAV systems should have either PI or PID controls.

Location of Static Pressure Sensor. VAV terminal units function properly within a certain inlet pressure range based on the supply air quantity and noise level. The supply air duct system must provide this pressure range at all locations of the terminal units at all system operating hours. This requirement is accomplished by properly locating the static pressure sensors. The selection of sensor locations is a compromise between fan energy savings and proper functioning of terminal units and supply air fan. For a diversified system, a maximum amount of energy may be saved when the sensor is located close to the end of the 
longest duct run. However, terminal units located close to the supply fan may be subjected to large pressure variations, and certain terminal units fed from other branches may not have the required pressure during other load conditions. A general recommendation is to locate the pressure sensor approximately two-thirds to three-quarters of the distance from the fan to the last terminal unit. The pressure setpoint of the static pressure controller must be adjusted upward to compensate for the duct friction between the pressure sensor and the last terminal unit so that the last unit will have the minimum pressure required for proper operation. In setting the pressure setpoint, all terminal units under the same system should be checked to make sure that all units' pressure requirements are satisfied. Yet, the setting should not be overly high to cause energy waste. For systems having multi-branch duct layout, multiple sensors may be required in order for all terminal units to meet the required pressure during all load conditions. Multiple sensors may also save system energy when multi-branch ducts have substantial differences in air friction. As mentioned previously, this also points to the importance of laying out a fairly balanced ductwork in terms of duct pressure during most of the system operating time. It is the responsibility of the system designer that analysis is made to locate the sensor (or sensors) properly. Duct pressure calculations at full and minimum loads should be made for single branch duct layouts. At least one more calculation at the midpoint of full and minimum loads should be made for multi-branch duct layouts. Calculation results should indicate that all terminal units will have proper static pressure. The static pressure sensor locations and pressure setpoint should be indicated in the construction document. Also see analysis of system static pressure profiles in CHAPTER 2 AIR HANDLING SYSTEM DESIGN.

Installation of Static Pressure Sensor. No matter where the static pressure sensor is placed, the specific duct configuration around the sensor requires careful consideration. It should not be installed near any elbows, transitions, or other locations where the air flow is swirl or not parallel to the duct wall. It should be located in the longest straight run of duct that can be practically identified. Additionally, the actual sensing tubes must be positioned correctly in the duct, perpendicular to the air flow. Pitot tubes affixed on steel plates or shop fabricated tube-plate sets should be used for the sensing.

High Limit Pressure Sensor. In order to prevent system damage, a high limit pressure sensor should be installed at the fan discharge to turn the system off when the high limit setting is exceeded. 


\subsection{BUILDING PRESSURE MAINTENANCE}

Keeping building pressure at a reasonably stable level is often a problem in VAV buildings. The general objective of building air balancing is to maintain a slight positive pressure in the building after the exhaust air requirement is met. Various designs have been used to try to achieve this objective. Building pressure maintenance remains controversial partly because of the diversity of building characteristics. It must be stressed that a system analysis including the entire air handling components (e.g. supply fan, return fan, exhaust or relief fan, duct system, as well as the control system) based on full and partial load conditions is the only way to assure successful operation after construction. System analysis on building air balance at full, minimum, and midpoint of the supply air flow is required, unless the airflow rates of the fans are controlled in feedback loops based on actual measured flow rates. The analysis should reflect the actual operation modes of all fan, interlocked or independently operated. Some of the often used controlling methods are briefly described below:

Supply and Return Fans Controlled by a Single Controller. This is the simplest arrangement. Both supply and return fans are controlled by a single controller that senses supply duct static pressure. When the building load changes, the airflow rates of both fans are changed according to their respective characteristic curves. If the fan characteristic curves are not matched properly, which very often happens at low partial load conditions, the building pressure will vary substantially from the pressure for which the conditions were designed and balanced. There are variations of this type of control. One example is to extend the building balanced conditions at low partial load conditions by measuring supply and/or return flow rates and by resetting supply and/or return fans. The arrangement of a single controller controls both supply and return fans with multiple static pressure sensors is shown in Figure 4.

Return or Relief Fan Controlled Independently From Space. In this scheme, the supply fan is controlled by a static pressure sensor in the supply air duct. The return or relief fan is controlled independently by a static pressure sensor located in the building to maintain a desired pressure level. Caution should be exercised in locating the space static pressure sensor. The sensor should not be located near building openings to the outside nor in a place where representative pressure of the building cannot be assured. The pressure setting of the controller should not be too high (no more than $37 \mathrm{~Pa}\left(0.15^{\prime \prime} \mathrm{H}_{2} \mathrm{O}\right)$ ), or pressure instability will occur when the outside doors are opened. Static pressure sensor locations and controller settings should be shown in the construction document. A return fan controlled by a space pressure sensor is shown in Figure 5 . 


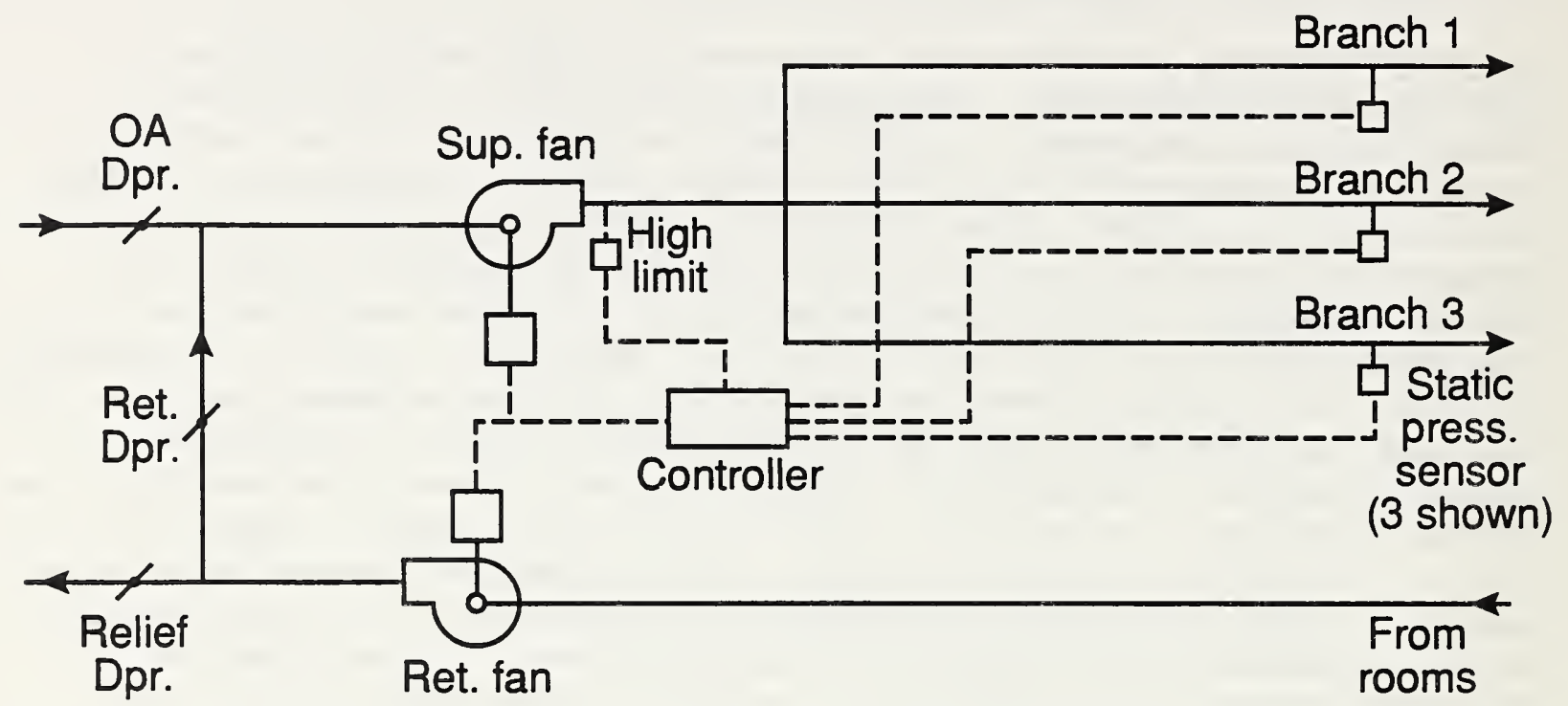

Figure 4 Control of Supply and Return Fans From a Single Controller

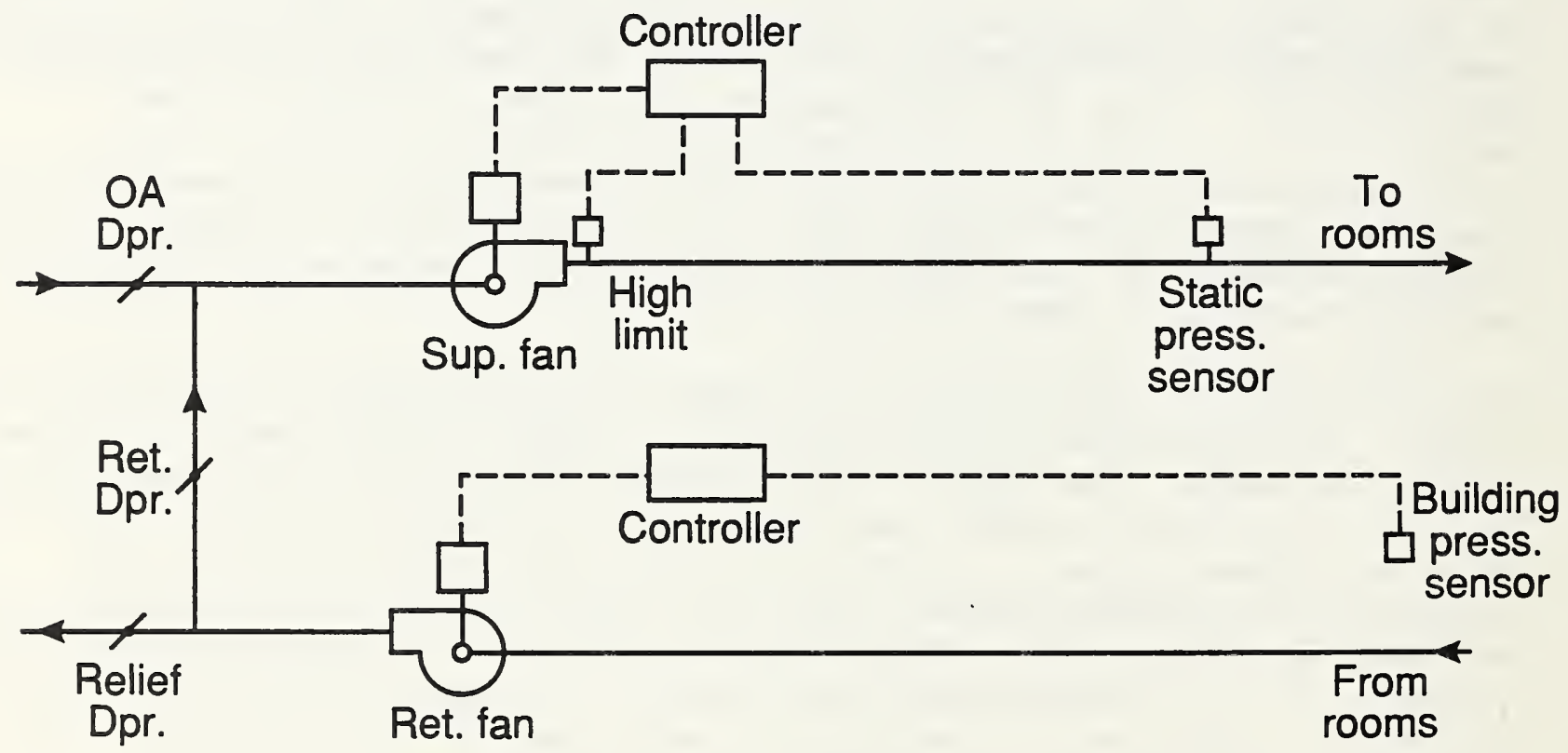

Figure 5 Control of Supply and Return Fans Independently 
Balance Building by Measuring Both Supply and Return Air. This scheme measures the airflow rates of the supply and return air fans at all times. The return air fan is controlled in a closed control loop to yield a constant amount of excess air in the building for pressurization (return air = supply air - exhaust air - excess air). This scheme is the most positive way of controlling building pressure and is the recommended scheme. However, there are drawbacks to this control. It is relatively expensive as compared to other control arrangements, because of the equipment (airflow measuring station and associated equipment, see another section for detailed discussion of requirements) needed to measure airflow and manipulation of the measured data. The controls should also be set carefully to avoid hunting. Figure 6 shows controls of this arrangement. A slight variation of this scheme is arrived by measuring velocity pressures, in lieu of airflow rates, to reset the return air fan. This variation does not give accurate control and should not be used (see CONTROL DETAILS section).

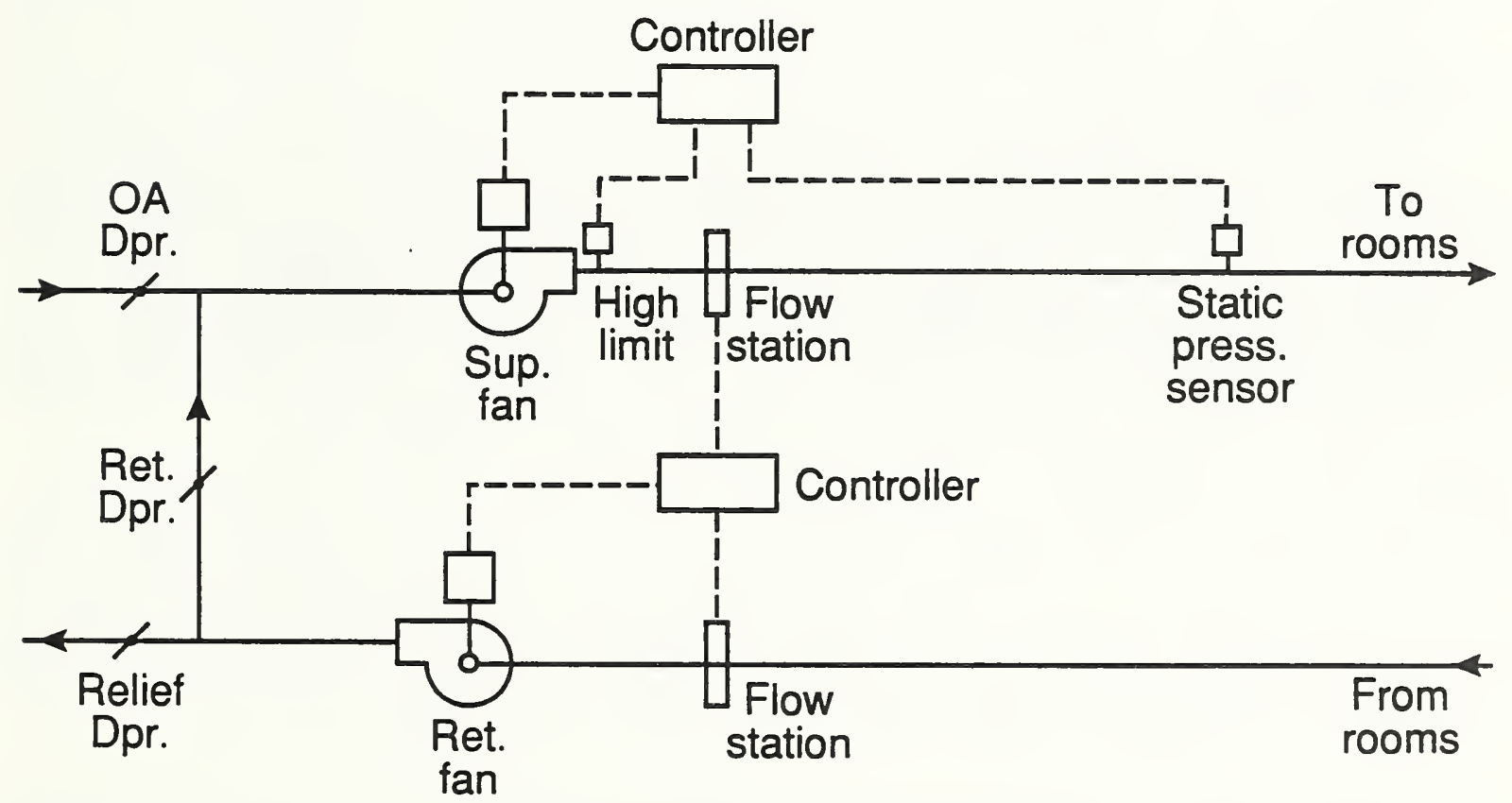

Figure 6 Control of Supply and Return Fans by Measuring Supply and Return Airflows 
Coordination with Architectural Details. Certain architectural arrangements may also affect a building's pressure performance. For example, a building's inside pressure may be designed as a reference to control fan operations. Many architectural designs have entrances vestibules to reduce the effects of outside temperature and wind influences when the entrance doors are opened. The fact is that both entrance and vestibule doors are frequently opened at the same time during heavy traffic periods. This may upset the building pressure and the fan operation. In order to maintain tighter building pressure, an alternative to the double door arrangement is to use revolving doors for the general public and powered automatic doors for physically handicapped persons.

Half-height cubicle partitions are used extensively in Federal buildings. These cubicles are installed in open office settings with overhead air supply for heating and cooling. It is more desirable to have open bottom type cubical panels (152 - $203 \mathrm{~mm}(6$ - 8") open spaces between bottoms of panels and the floor) to aid air circulation in a VAV building than in a building with constant volume air supply. Good coordination between HVAC designers and architects should solve such problems and improve VAV system performance.

\subsection{OUTDOOR AIR}

A major problem in VAV systems is caused by the reduced outdoor air during partial load. The amount of outdoor air of many designs depends solely on the pressure difference between the mixing plenums of air handling units and the outdoor. This pressure difference changes constantly depending on the building load. When the building load is reduced and the capacity of the supply fan is decreased, the outdoor air is usually reduced and in many instances may be reduced to unsatisfactory amounts. Even though recent field tests indicate that most new Federal buildings designed in the 1980's do not show unhealthy carbon dioxide levels during occupied hours, building design should make certain that the outdoor air requirements as recommended in the ASHRAE Standard 62-1989 (Ventilation for Acceptable Indoor Air Quality) are not violated. For offices and conference rooms the ASHRAE Standard recommends $9.4 \mathrm{~L} / \mathrm{s}(20 \mathrm{cfm})$ of outdoor air per person.

Economizer Cycle. Although the air side economizer cycle is not a unique energy saving strategy for VAV system, the airflow variations in a VAV system require special attention during system design. The economizer cycle changes the pressure relationship inside the plenums of the air handling unit and adds complications to the outdoor air problem as described in the previous paragraph. In selecting an economizer cycle between enthalpy or dry-bulb type, the quality of future building 
services should be heavily weighed. The enthalpy economizer cycle may be used if it can be assured that appropriate service to the humidity sensors may be obtained in the future. Otherwise, the dry-bulb temperature type should be used. The change-over temperature of the cycle should be calculated to have optimum yearly energy usage for the weather conditions of the location.

Assurance of Adequate Outdoor Air. In an ordinary VAV supply and return fan setup, the pressure differential between the return air duct (at return fan discharge duct which is usually under positive pressure) and the air mixing chamber (which is usually under negative pressure) is relatively large. This causes more than the desired amount of return air to enter the air handling unit and reduces the amount of outdoor air in the system. In order to correct this pressure imbalance, the return air damper must provide enough friction to reduce this pressure difference. The return air damper should be specified for opposing blades and should be sized for at least $7.6 \mathrm{~m} / \mathrm{s}(1,500 \mathrm{fpm})$ air velocity. Show return air damper sizes on drawings.

A research project sponsored by ASHRAE to study the relationships of outside air, economizer cycle, and building pressure problems in VAV systems is currently being conducted. Before this research is completed and recommendations are given, all VAV systems designed for Federal office buildings should have return air damper controls or other means to provide the required outdoor air during the entire occupied hours. One method to achieve this is by sensing the outside air velocity or airflow rate at the outside air intake ducts to set the positions of return air and outside air damper blades. Depending on the system layout, it may be difficult to find ideal locations for installing these sensors. Every effort should be made to locate these sensors to give correct outside air readings.

\subsection{CONTROL DETAILS}

Reference Pressure. A reference pressure (outside or inside the building) is often used to set the correct building or duct pressure control. This reference pressure has often been incorrectly secured. Designers must indicate the locations of the reference pressure sensors and specify the required construction in the construction document. Projects must not rely on the discretion of the control contractors for such installations.

A reference pressure should not be influenced by wind, door opening and closing, or other pressure changes caused by occupants' action or equipment operation. Pressure sensing tip located on an outside wall is often influenced by wind speed and direction changes. Incorrect 
readings are frequently caused by the wind flow around surrounding buildings or around the building itself. A good location for an atmospheric reference pressure is on the open roof, with the pressure instrument housed in a louvered weather enclosure. To locate pressure sensing tips for indoor reference pressure, a large open area such as an atrium is ideal. Avoid first floor locations because of entrances and pressure gradients caused by the stack effect. Prefabricated pressure measuring units including pressure sensing tips and partially enclosed enclosures should be used to further reduce the influence of local air movement.

Alrflow Measuring Station. There are basically two different designs of airflow measuring stations available on the market. One design mechanically detects the velocity pressure (using the differential pressure principle) of the air stream; the other uses thermal devices for velocity detection. Air straightening vanes must be included in the stations, and the stations must have enough local velocity detections to give average velocity readings within $3 \%$ of the true flow at peak airflow rates. In selecting and locating airflow measuring stations, care must be taken so that the anticipated low airflow rates can still be measured within the desired tolerances. For the differential pressure type, the air velocity at low airflow should not be below $3 \mathrm{~m} / \mathrm{s}$ (600 fpm). The airflow measuring station and duct sizes should be reduced, if necessary, to increase the measurement accuracy and to avoid losing control at low flow conditions. In case the duct layout does not permit a single measuring station for the measurement, individual. measuring stations in main branches should be provided.

Conversion of Velocity Pressure to Flow. All air velocity pressure measurements must be converted to air velocity, so that the air flow rates of the supply and the return air fans may be manipulated to yield the desired amounts for building pressure control or for outdoor air control. This conversion can be readily performed by software programs in direct digital control (DDC) systems. For pneumatically controlled systems, a square-root extracting device is needed. This device converts the velocity pressure signal into a velocity signal, and in turn the signal is changed into airflow rates. Some simplified designs (either by project designers or by control contractors) use a shortcut to approximate the conversion by using the velocity pressure signal directly on the control transmitters. This requires very careful selection and tuning of the control systems. Under the current maintenance environment, successful results are difficult to achieve. Therefore, all projects should have true airflow rates converted before these rates are used to control fans.

Cooling and Heating Control. Figure 7 demonstrates a recommended heating and cooling sequence of an exterior space having heating coils (with reheat coil in the terminal unit or finned-tube under the window). 
The requirement of avoiding simultaneous cooling and heating has been stated earlier. When the cooling load is decreasing, the VAV terminal units should reduce the airflow rates to the spaces in response to the demands as reflected by the space temperature sensors. After the

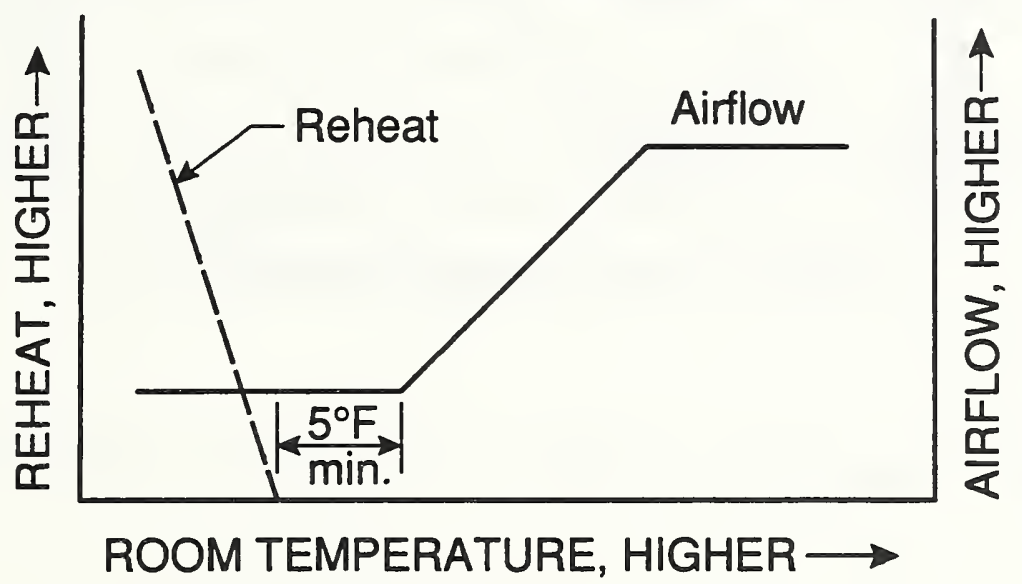

Figure 7 Temperature Control of Single-Duct VAV
or Single-Duct VAV With Heating

minimum airflow rates are reached, this airflow from the air handling system should be maintained. If the amounts of the specified minimum supply air to spaces are large as compared to the space loads, the space temperature may drop to a point where the room comfort is compromised. Raising the cooling coil discharge temperature may be used to alleviate this shortfall. However, raising the discharge air may result in unacceptable space humidity and will increase the fan power consumption. The consequences of this temperature reset should be evaluated and the magnitude of the reset should not be over $1.7^{\circ} \mathrm{C}\left(3^{\circ} \mathrm{F}\right)$. If the chilled water system allows, the chiller temperature control should also be reset upward. When the air temperature is raised, it should be done after all key zones have reached the minimum supply air amount. The decision must be made by comparative energy calculations. Fan-powered terminal units have the advantage of recirculating the warm ceiling air to the room spaces. The control of fan operation should be in sequence with the cold air reduction. The heating system should not be on unless the cooling damper reaches its minimum position. The recommended temperature control sequence of these units is depicted in Figure 8 . 


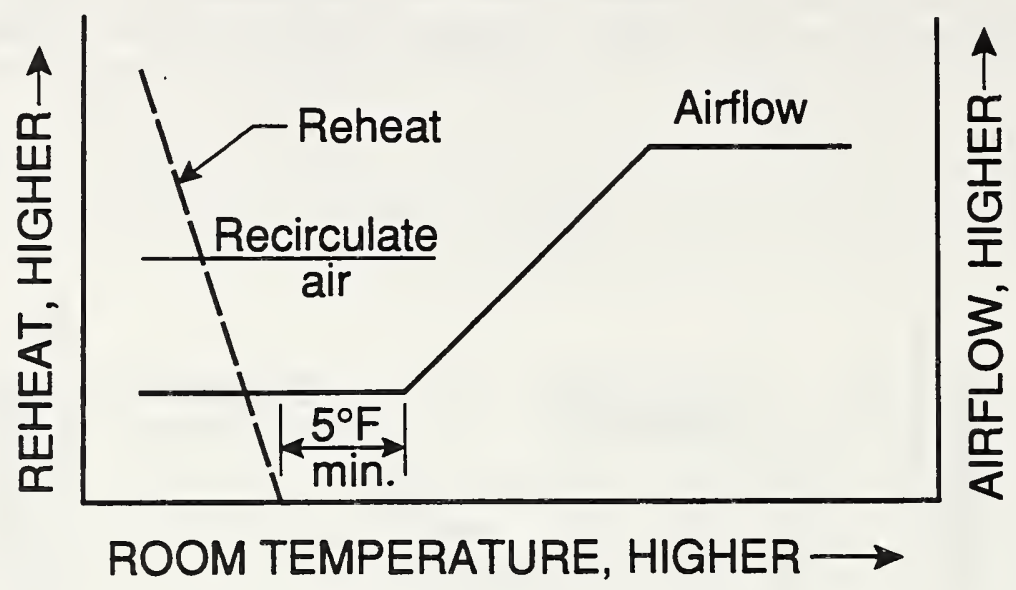

Figure 8 Temperature Control of Fan-Powered (Parallel) VAV

Night Control. In the heating season, night temperature setback should be designed for $12.5^{\circ} \mathrm{C}\left(55^{\circ} \mathrm{F}\right)$ indoors. The space temperature should be floating above $12.5^{\circ} \mathrm{C}\left(55^{\circ} \mathrm{F}\right)$ without invoking heating. During the morning warmup, if the air handling unit is designed to provide heating, controls of VAV terminal units should be under room temperature control, so that overheating of rooms may be prevented. For a system serving interior spaces, the morning cool-down period in the cooling season needs attention. During this period, dampers of many terminal units are wide open. For certain types of fans, this may produce undesirably high airflow and power rating. Check fan motor rating or provide control to prevent overloading. The outside air damper should be closed and exhaust fans should be off during the warmup and cool-down periods. Since there is no air exhaust during these periods and the supply and return fan controls may remain the same as during the day time operation, pressures in ducts and in the building should be checked to avoid extremes.

Control Instrumentation. Inspection of existing Federal office buildings reveals that many indicating instruments which are necessary for good building operation are not installed or properly maintained. This is due to the lack of clear requirement of the construction specifications of these projects. Their requirements should be determined and specified by the designers instead of relying on the judgment of the control contractors. Depending on the system design, the required instruments should include the following: 
Airflow rate gauge for airflow measuring station

Airflow rate gauges for supply and return air fans

Airflow rate or velocity gauge for outside air, if the outdoor air is measured

Duct static pressure gauge for supply air fan control, all static pressure gauges if multi-pressure measurement is used

Static pressure gauge for building pressure

All key zone temperature gauges if cold air temperature is reset by zone temperature

Temperature gauge for outdoor air. 


\section{CHAPTER 4. COMMISSIONING}

Commissioning serves to improve project quality through the validation of project design and the verification of building construction. This process is intended to functionally test and evaluate the systems before they are accepted by the Government and commissioned into building service. Even though commissioning processes start during the early stages of the building design, the final acceptance tests should be performed after construction contractors have gone through startup procedures of major equipment, completed all balancing and adjusting of HVAC equipment and systems, and fine tuned all control devices. Keep in mind that VAV systems in a building are only portions of the entire building's systems. In order to have VAV systems function correctly, the related systems must perform appropriately. Therefore, the prerequisite of commissioning of VAV systems is the normal functioning of building architectural construction (particularly important are building envelopes, partitions, windows, and entrance openings), the central cooling plant (for the correct chilled water supply), the central heating plant and space heating system, and other air handling systems which may affect the building air balance. A GSA publication "Functional Inspection and Testing of HVAC Systems in Federal Buildings" may be consulted for general discussions and requirements of commissioning.

The construction document of a project should include commissioning instrument requirements, commissioning procedures, and commissioning criteria specified so that the bidding contractors may have clear understanding of the project requirements and objectives. Commissioning tests should be performed by the installation contractor or a separate commissioning contractor. Tests must be witnessed by Government personnel or their designated representatives. All test results should be recorded by the contractor and turned over to the Government as part of the operation and maintenance manual. The following sections may be used as guidelines for testing VAV systems specifically:

\subsection{VAV TERMINAL UNIT}

Terminal Units to be Tested and Failure Criteria. Randomly test a minimum of $10 \%$ of VAV terminal units which are supplied from the same air handling system. If $10 \%$ of these units' airflow rates (see next 
paragraph) differ by more than $10 \%$ of the specified rates, a second set of $10 \%$ of units should be selected for testing. The entire VAV system must be rebalanced, necessary controls retuned, and testing repeated, if (i) any $10 \%$ of the units measured have airflow rates off $+/-15 \%$ from those specified; or (ii) the total of all measured airflow rates of the selected terminal units differs over $+/-10 \%$ from the total of the designed airflow rates.

Airflow Test Procedure. During the first part of the test, the supply air duct static pressure at the pressure sensing location should be checked to make sure that the specified pressure is maintained. Measure the maximum and the minimum airflow rates of the selected units by manipulating the damper controller input signals of the unit dampers. During the second part of this test, raise the supply duct static pressure approximately $249 \mathrm{~Pa}\left(1 " \mathrm{H}_{2} \mathrm{O}\right)$ and perform the same measurements as described for the first part of the test. Judgment should be used in raising the duct pressure so that the high pressure limit is not exceeded.

Unit Fan and Heating Control Testing. Verify the terminal unit fan (for fan powered unit), heating damper (for dual-duct VAV), and/or heating control valve (for reheat unit and fan-powered heating unit) operation by manipulating input signals to space temperature sensing devices. The operation of these devices should agree with the specifications.

\subsection{AIR OUTLET}

Smoke Test. A smoke test of the airflow pattern of the air outlet cannot quantitatively substitute for room temperature and air velocity tests as required in the ADPI testing. However, it is a simple and visually observable method to test airflow pattern in the space and is suggested in these guidelines for room airflow pattern tests. Note that the selection of air outlets during design is based on ADPI values (see CHAPTER 2. AIR HANDLING SYSTEM DESIGN). This test is used to verify the correct adjustment of vane positions.

Testing Procedure. Similar to VAV terminal units, randomly test a minimum of $10 \%$ of air outlets which are supplied from the same air handling system. For systems which service both perimeter and interior rooms, one-half of the outlets should be for the perimeter and the other half for the interior. The smoke test should be used to visualize the airflow patterns for adjusting air outlet vanes. Especially important is testing the airflow pattern at minimum airflow rates. If over $10 \%$ of these air outlets require readjusting of vanes, all air outlets of the system should be tested. The air outlet test should be coordinated with the VAV terminal unit test, since both tests require the maximum and the 
minimum airflow from the units.

\subsection{AIR HANDLING SYSTEM}

Supply/Return Fan Control. It is difficult to simulate a true cycle of building load change to see how the air handling system responds to the load changes. It is much simpler instead to reset the static pressure setting of the supply air duct and to evaluate the responses of the supply, the return, or the relief fans. Two main objectives should be achieved during the air handling system test: to verify stable operation of the fans at low building load, and to verify the return and/or relief fan operation in response to the supply air fan changes.

The static pressure setting of the supply air duct can be lowered gradually by manipulating the supply fan controller or by directly feeding a known pressure at the pressure sensing line. The supply fan airflow rate should be observed or measured until the calculated low system airflow rate is reached. The airflow rate of the return air fan should also be observed. The excess air left in the building may be calculated by these data and the measured exhaust air data. During the entire test, all fans should show no sign of surging or other unstable indications.

Outdoor Air. During the supply/return air fan test, the amount of outdoor air entering the building through the air handling unit should be monitored by direct measurement or other means (e.g. tracer gas method). The amount of outdoor air should not be less than the minimum amount designed. Manipulate the economizer cycle control to open the outside air dampers to simulate the economizer cycle (together with the return and relief dampers as designed).

Building Air Pressure. If the return or relief fan is controlled by sensing the building pressure, the building pressure and fan operation should be monitored to assure appropriate operation. This test should be conducted during the supply/return fan control test and the outdoor air test as described above.

The Smoke test at building openings on all floors (entrance doors, loading docks, etc.) should also be used to assure that the building is under positive air pressure at all operating conditions. 


\section{CHAPTER 5. DESIGN CHECK LIST}

This chapter lists recommended design practices, required design information for construction documents, and required design analysis to be submitted to PBS. Some of the recommended design practices should be evaluated in conjunction with design analysis, since their application may depend upon the results of the design analysis. These recommendations are believed to be applicable to the majority of Federal buildings and are presented to assist designers as a "check list" during design. If a particular recommendation does not correspond with the design criterion of the building being designed, the designer should refer to appropriate discussions in previous chapters for guidance.

\subsection{RECOMMENDED DESIGN PRACTICES}

1. Perform room heating and cooling load calculations to determine maximum and minimum supply air quantities, outdoor air amount, and required air temperature of the system.

2. Perform system block load calculations at least for 9 A.M., 12 noon, 2 P.M. and 4 P.M. to determine system peak load. Each air handling system must have block calculations.

3. Design $9.4 \mathrm{~L} / \mathrm{s}(20 \mathrm{cfm})$ per person outdoor air for offices.

4. Do not design room peak supply air below $3.6 \mathrm{~L} / \mathrm{s}$ per square meter ( $0.7 \mathrm{cfm}$ per square foot) of floor area.

5. Do not design minimum supply air for offices below $30 \%$ of peak supply air.

6. Calculate room loads at minimum air supply to check space humidity levels.

7. Evaluate room load characteristics and program requirements to determine thermal zones.

8. Do not size perimeter zones over $93 \mathrm{~m}^{2}\left(1,000 \mathrm{ft}^{2}\right)$ floor area. Do not size partitioned interior zones over $93 \mathrm{~m}^{2}$ $\left(1,000 \mathrm{ft}^{2}\right)$ floor area. Do not size interior open-office 
over $232 \mathrm{~m}^{2}\left(2,500 \mathrm{ft}^{2}\right)$ floor area.

9. List maximum and minimum supply air quantities for each room (or each VAV terminal unit) on the drawings.

10. Design separate air handling systems for court rooms. Do not drop supply air to court rooms below $50 \%$ of maximum supply air. If cooling load in a court room is expected to be less than $50 \%$ of the peak load, provide reheating or bypass the supply air.

11. Except for fans, use system peak block load to size air handling equipment.

12. Size supply fans based on system diversification (approximately 60 - $80 \%$ of peak block load flow rate).

13. Use a return or relief fan, if the friction along the return duct is over $62 \mathrm{~Pa}\left(0.25 " \mathrm{H}_{2} \mathrm{O}\right)$.

14. Check supply and return fan performance for the entire anticipated load range (from full flow to minimum flow). System pressure-flow curve must be adjusted for duct pressure variations. The fan operation in the entire flow range must be stable.

15. Do not use forward-curved fans in built-up units. For packaged units, do not use forward curved fans for wheel sizes over 0.5 meter (20 inches).

16. Check motor sizes for the entire system airflow range.

17. Do not use parallel fan arrangement with individual drives.

18. Select airfoil-blade fans whenever possible.

19. When selecting fan types, compare the total costs of fan, noise treatment equipment, and the required floor space.

20. Do not use discharge dampers for airflow control.

21. For centrifugal fans, use inlet vanes or variable frequency drives for systems having $4,720 \mathrm{~L} / \mathrm{s}(10,000 \mathrm{cfm})$ or less; use variable frequency drives for systems larger than 4,720 $\mathrm{L} / \mathrm{s}(10,000 \mathrm{cfm})$ capacity.

22. Inlet vanes must be factory designed matching-set for the fan. 
23. Specify pulse width modulation type invertor for variable frequency drives.

24. Use variable pitch controls for vaneaxial fans.

25. When detailing on drawings or specifying thermal insulation and jackets, alert contractors that jackets shall not interfere with fan speed control mechanism.

26. Specify airflow rates and pressures for fans at both maximum and minimum capacities. Require contractors to submit fan curves to prove stable operation within this expected range.

27. Use pressure regain method to size supply ducts except for branch ducts where the air velocity drops below $6.4 \mathrm{~m} / \mathrm{s}$ $(1,250 \mathrm{fpm})$.

28. Use round or oval ducts from air handling unit to VAV terminal units.

29. Observe recommended straight duct length between fittings.

30. Arrange duct layout to avoid large pressure differentials between branches. Use interconnecting (or loop) arrangement when it is helpful to reduce large pressure difference between branches.

31. When using ceiling space as return plenum, evenly distribute return air collecting inlets above ceiling. Do not return over $18,88 \mathrm{~L} / \mathrm{s}(4,000 \mathrm{cfm})$ at one collecting location.

32. The distance between ceiling return air grille from air collecting inlet in ceiling space (when using ceiling space as return plenum) shall not be over $45 \mathrm{~m}$ (150 ft).

33. Do not use ceiling return grille within $6 \mathrm{~m}$ (20 ft) from air collecting inlet above ceiling whose peak return airflow is over $944 \mathrm{~L} / \mathrm{s}(2,000 \mathrm{cfm})$. Design low return air grilles in these areas instead, to minimize supply-return short circuiting.

34. Use ceiling diffusers that direct supply airflow horizontally. Linear diffuser is a good example. Select diffusers having high entrainment character at low airflow.

35. Do not use light troffers without horizontal air deflecting blades for supply outlets.

36. Consider adverse effects of ceiling obstructions and breaks 
when locating diffusers.

37. Specify and select VAV terminal units to provide accurate airflow $(+/-10 \%)$ at low flow ranges.

38. Design general offices for RC35 and conference rooms for RC30.

39. Do not provide heating capability in interior offices. Provide reheating in high latent room to limit space humidity to under $55 \%$ R.H.

40. For exterior spaces, provide perimeter convective heating system (hot water finned-tubes), double-duct VAV units, or fan powered VAV units for heating (see text on SPACE HEATING SYSTEM).

41. Room temperature setting of space temperature controllers shall have a minimum of $2.8^{\circ} \mathrm{C}\left(5^{\circ} \mathrm{F}\right)$ separation between heating and cooling.

42. Provide proportional-integral controls for supply and return fans, and coil temperature controls.

43. If a multi-branch system has substantial changes in duct pressure, use multiple static pressure sensors to control supply fan.

44. Locate supply fan static pressure sensor(s) approximately two-thirds to three-quarters distance from the supply fan. Make sure the sensor(s) receives adequate air velocity, 3 $\mathrm{m} / \mathrm{s}(600 \mathrm{fpm})$ minimum, at all building load conditions.

45. Pressure setting of the supply fan controller must be specified to maintain all VAV terminal units in proper operating range. Do not specify unnecessarily high pressure setting.

46. All VAV terminal units must be checked for proper duct pressure throughout the operating range of the system.

47. Do not locate static pressure sensors close to elbows or other duct fittings which may cause air turbulence.

48. Provide high pressure limit at supply fan discharge to prevent damage to duct system.

49. Provide prefabricated airflow measuring stations for both supply and return systems. 
50. Size airflow measuring stations to give accurate readings at minimum duct airflow. For stations using differential pressure principle, the air velocity must not be below $3 \mathrm{~m} / \mathrm{s}$ (600 fpm).

51. Select airflow measuring stations measuring within $3 \%$ accuracy of rated airflow. Airflow measuring stations must have built-in straightening vanes.

52. Design return or relief system to maintain proper building pressure. The recommended scheme is to control the return/relief fan to give a fixed amount of excess air in the building for pressurization. The return/relief airflow rate (in airflow rate units) must be from measurement.

53. If return/relief fan is controlled by the feedback of building pressure, the pressure setting must not be higher than $37 \mathrm{~Pa}\left(0.15 " \mathrm{H}_{2} \mathrm{O}\right)$.

54. Locate building pressure sensor to represent average building pressure. Do not locate sensor close to entrance doors or other location where the pressure fluctuates. Atrium above first floor is generally a good location.

55. Do not use enthalpy economizer cycle unless proper maintenance of humidity instruments can be assured. Use dry bulb economizer cycle. Specify changeover temperature for dry bulb economizer cycle.

56. If enthalpy economizer cycle is used, do not locate outdoor humidity sensor where saturation or contamination of sensor may occur.

57. Proper pressure differential between the two sides of return air dampers must be maintained regardless of the building load (high or low airflow) and economizer cycle mode (on or off) so that the proper outdoor air can be assured. Do not size return air dampers at less than $7.6 \mathrm{~m} / \mathrm{s}(1,500 \mathrm{fpm})$ velocity. Use opposed-blade dampers.

58. Do not locate reference pressure sensor at locations where the pressure fluctuates. Do not allow sensor tips installed on outside walls without protection. Use perforated enclosures or locate sensors in properly designed weather stations.

59. Use air pressure/velocity conversion device (square-root extractor) or software to obtain true air velocity and airflow rate from velocity pressure signal. Do not allow 
pressure/velocity approximation.

60. Do not reset discharge air temperature over $1.7{ }^{\circ} \mathrm{C}\left(3^{\circ} \mathrm{F}\right)$. When reset is planned, compare fan energy increase with the benefit of resetting temperature.

61. Do not initiate space heating operation (finned-tubes or supplied from VAV terminal unit), unless VAV terminal units are at minimum airflows.

62. Require indicating instruments to assist system operation and trouble-shooting. Instruments included are, but not limited to, airflow rate gages for supply fan, return fan, and all airflow measuring stations; pressure gages to indicate building pressure and duct pressure for supply air fan pressure control; and temperature gages for outdoor air and all key spaces.

63. Coordinate with architects on type of entrance doors to minimize building pressure fluctuations.

64. Do not use half-height partitions with closed bottoms. Coordinate with architects or interior designers to specify open-bottom panels to assist air circulation.

65. Specify commissioning requirements to test VAV terminal units to verify control sequence and airflow rates between specified maximum and minimum static pressures.

66. Specify commissioning requirements to verify responses of supply/return/relief fans to load changes, system stability, and building pressure maintenance.

67. Specify commissioning requirements to verify outdoor air rate during economizer cycle.

68. Specify commissioning requirement to verify air flow patterns in spaces for both maximum and minimum airflows.

\subsection{ITEMS TO BE INCLUDED IN CONSTRUCTION DOCUMENT}

The following information is required in the construction documents. This list represents only the minimum requirements which are specific to VAV systems. Other requirements for general air handling systems are not shown below. Designers should include all other requirements (VAV specific or not) in the construction documents to enhance the quality of the project. 
Outdoor air:

The minimum amount of outdoor air which must be admitted to the system during occupied hours.

Supply air fan: Fan selection-point airflow rate and total pressure, approximate wheel diameter, motor size, airflow rate and total pressure at calculated minimum system airflow. Maximum sound power level and blade frequency increment at peak airflow. Require fan manufacturer to assure satisfactory operation in submittal.

Return air fan: Similar to supply air fan.

VAV terminal unit: Maximum and minimum airflow rates, minimum static pressure required for unit functioning, maximum static pressure unit may be subject to (from system pressure analysis) and noise ratings at maximum pressure and minimum airflow.

Supply air outlet: Face and neck sizes, ADPI performance for both maximum and minimum airflow rates if the minimum airflow is less than $50 \%$ of the maximum airflow, ADPI performance for the maximum airflow only if the minimum airflow is more than $50 \%$ of the maximum airflow.

Supply duct static pressure:

Controller pressure setting and sensor location, including reference pressure location. For multiple sensor, indicate all sensor locations. Also indicate pressure setting for supply fan high limit.

Other static

pressure devices: Controller pressure settings and sensor locations, including reference pressure locations.

Airflow measuring station:
Maximum and minimum airflow rates, air friction at maximum airflow. Station must be able to measure the minimum airflow rate. Locate airflow measuring stations on contract drawings.

Control

instrumentation: Indicate all required indicating instruments and locations. 
System operation and maintenance procedures:

Commissioning requirements :
Operating procedures, possible failures, trouble shooting, and corrective measures to be included in operation and maintenance manual.

Commissioning requirements on the air handling system (including fans, building pressure, and outdoor air), supply air outlets, and VAV terminal units.

\subsection{DESIGN ANALYSIS TO BE SUBMITTED TO PBS}

A thorough system analysis during the design stage is really the key to future successful system operation. The following required submissions are intended to assure good design practices that thorough VAV system analysis are performed. Other required analysis and submissions usually required by $P B S$ for non-VAV systems are not included here. They must also be performed and submitted.

System selection: If a VAV system is not selected for the office area, economical justification on the system selected as compared to a VAV system.

Room load and supply air calculations :

System load and supply air calculations:

System static pressure analysis:
Include maximum and minimum supply air quantities, room humidity at minimum air for low sensible ratio rooms and typical general offices.

Include system air at peak and minimum block loads. For system serving multi-exposure spaces, load calculations must include those at 9 A.M., 12 noon, 2 P.M., and 4 P.M. Include block loads at other times if needed.

Calculate and plot system static pressure profiles at peak (with and without economizer cycle), and minimum airflows. For system having multi-branches, show system static profile at midpoint of maximum and minimum airflows. 
Static pressure profile should indicate pressure levels to include at least the following points: at the outdoor (zero), air handling unit mixing plenum, supply fan inlet, supply fan outlet, at least the first and the last VAV terminal unit inlet, room, return fan inlet, return fan outlet, at return air dampers, inside relief dampers, and the outside (zero). For system having multi-branch duct layout, the first and the last VAV terminal units of each branch shall be included.

Noise calculations: From supply air fan to rooms with the shortest duct run at peak system airflow. Also calculate the room noise level of these rooms at low airflow and peak fan outlet pressure. 
Variable Air Volume System Design Guide 


\section{REFERENCES CONTAINING USEFUL DESIGN DATA}

1. General Services Administration Public Building Service Quality Standards for Design and Construction (PBS P 3430.1A)

2. ASHRAE Handbook 1987 HVAC Systems and Applications Volume, Chapter 52 Sound and Vibration Control

3. ASHRAE Handbook 1989 Fundamentals Volume, Chapter 31 Space Air Diffusion and Chapter 32 Duct Design

4. ASHRAE Standard 113-1990 Method of Testing for Room Air Diffusion

5. Sheet Metal and Air Conditioning Contractors National Association (SMACNA) HVAC Duct System Design, 1977 



\begin{tabular}{|c|c|c|}
\hline \multirow[t]{3}{*}{$\begin{array}{l}\text { NIST-114A } \\
\text { (REV. 3-89) }\end{array}$} & \multirow{3}{*}{$\begin{array}{l}\text { U.S. DEPARTMENT OF COMMERCE } \\
\text { NATIONAL INSTITUTE OF STANDARDS AND TECHNOLOGY } \\
\text { BIBLIOGRAPHIC DATA SHEET }\end{array}$} & $\begin{array}{l}\text { 1. PUBLCATION OR REPORT MUMBER } \\
\text { NISTIR } 4605\end{array}$ \\
\hline & & PERFORMING ORQANIZATION REPORT NUMBER \\
\hline & & $\begin{array}{l}\text { 3. PUBLCATION DATE } \\
\text { JUNE } 1991\end{array}$ \\
\hline
\end{tabular}

4. TITLE AND SUBTITLE

Variable Air Volume System Design Guide

5. AUTHOR(S)

James Y. Kao

6. PERFoRMINO ORGANIZATION (IF JOINT OR OTHER THAN NIST, SEE INSTRUCTIONS)

U.S. DEPARTMENT OF COMMERCE

NATIONAL INSTTTUTE OF STANDARDS AND TECHNOLOQY

GATTHERSBURG, MD 20899

7. CONTRACT/QRANT NUMBER

8. TYPE OF REPORT AND PEAIOD COVERED

9. SPONSORING ORGANIZATION NAME AND COMPLETE ADDRESS (STREET, CITY, STATE, ZIP)

General Services Administration

Washington, DC

10. SUPPLEMENTARY NOTES

DOCUMENT DESCRIBES A COMPUTER PROQRAM; SF-185, FIPS SOFTWARE SUMMARY, IS ATTACHED.

11. ABSTRACT (A 200-WORD OR LESS FACTUAL SUMMARY OF MOST SIGMIFICANT IMFORMATION. IF DOCUMENT INCLUDES A SIQNIFICANT BIBUOQRAPHY OR UTERATURE SURVEY, MENTION IT HERE.)

Variable air volume (VAV) systems have been used extensively in office buildings during recent years. However, there are persistent complaints by building occupants about the air quality and environmental conditions of these buildings. This guide has been developed to give guidelines on VAV system design to alleviate possible design-caused problems. This guide provides general discussion of VAV systems, air handling system design, system control, and comissioning.

This guide has been developed for the General Services Administration to be used by GSA personnel and GSA's contract designers. It includes design check lists as a means of identifying major aspects in VAV system design where new construction and alteration of air systems are involved.

12. KEY WORDS (6 TO 12 ENTRIES; ALPHABETICAL ORDER; CAPITALZE ONLY PROPER MAMES; AND SEPARATE KEY WORDS BY SEMICOLONS) air conditioning; air handling system; automatic control; building design; design practice; variable air volume system

13. AVALABIUTYY

\begin{tabular}{|c|}
\hline \\
\hline \\
\hline
\end{tabular}

UNLIMITED

FOR OFFICIAL DISTRIBUTION. DO MOT RELEASE TO NATIONAL TECHMICAL IHFORMATION SERVICE (NTIS).

ORDER FROM SUPERINTENDENT OF DOCUMENTS, U.S. GOVERMMENT PRINTING OFFICE, WASHINOTON, DC 20402.

ORDER FROM MATIONAL TECHNICAL INFORMATION SERVICE (NTIS), SPRIMGFIELD, VA 22161.

14. NUMBER OF PRINTED PAQES

53

15. PRICE

A04 


